\title{
Spinitectus osorioi (Nematoda: Cystidicolidae) in the Mexican endemic fish Atherinella alvarezi (Atherinopsidae) from the Atlantic River drainage system in Chiapas, Southern Mexico
}

\author{
František Moravec $^{1 /+}$, Guillermo Salgado-Maldonado², Juan M Caspeta-Mandujano³ \\ ${ }^{1}$ Institute of Parasitology, Biology Centre of the Academy of Sciences of the Czech Republic, Branišovská 31, 37005 České Budějovice, \\ Czech Republic ${ }^{2}$ Instituto de Biología, Universidad Nacional Autónoma de México, México DF, Mexico ${ }^{3}$ Centro de Investigaciones \\ Biológicas, Universidad Autónoma del Estado de Morelos, Morelos, Mexico
}

Specimens of Spinitectus osorioi Choudhury and Pérez-Ponce de León, an intestinal nematode species previously considered to be specific to Chirostoma spp and endemic to some lakes in the Pacific drainage in Michoacán, were collected from the freshwater fish Atherinella alvarezi (Díaz-Pardo) (Atherinopsidae) of the Michol River near Palenque, Chiapas, Southern Mexico, which belongs to the Atlantic drainage system. Studies using light and scanning electron microscopy revealed some taxonomically important, previously unreported or erroneously reported features of S. osorioi, such as the location of the vulva, the actual number and distribution of postanal papillae and phasmids and the presence of a short median cuticular ridge anterior to the cloacal opening (in addition to two long subventral ridges). The recorded somewhat shorter spicules (420-465 and 105-111 $\mu \mathrm{m})$ and mostly smaller eggs (33$36 \times 18-20 \mu \mathrm{m})$ as compared to the original species description may be due to a different type of host, geographical region or generally smaller body measurements of these specimens. These biometrical differences are considered to be within the limits of the intraspecific variability of S. osorioi. A key to species of Spinitectus parasitizing freshwater fishes in Mexico is provided.

Key words: parasitic nematode - Spinitectus - freshwater fish - Atherinella - Chiapas - Mexico

To date, six species of Spinitectus Fourment (Nematoda: Cystidicolidae) have been recorded from freshwater fishes in Mexico (Choudhury \& Pérez-Ponce de León 2001, Moravec et al. 2002, Caspeta-Mandujano et al. 2007). Choudhury and Pérez-Ponce de León (2001) described Spinitectus osorioi Choudhury and Pérez-Ponce de León, an intestinal parasite of atherinopsid fishes $C h i$ rostoma attenuatum Meek and Chirostoma estor Jordan from Lake Pátzcuaro, Michoacán, mentioning that all former records of Spinitectus carolini Holl from Mexico refer to $S$. osorioi. Consequently, considering the paper by Espinosa-Huerta et al. (1996), they reported S. osorioi from these two host species from Lakes Pátzcuaro and Zirahuén, both the neovolcanic lakes of the Central Highland Plateau of Mexico. Later, S. osorioi was also reported from these two lakes by Lira-Guerrero et al. (2008), who had recorded it from C. attenuatum, C. estor and Chirostoma grandocule (Steindachner). All Chirostoma spp are endemic to the Lerma River basin (Froese \& Pauly 2009) and, therefore, S. osorioi has been considered by both Choudhury and Pérez-Ponce de León (2001) and Lira-Guerrero et al. (2008) to be a specific

Financial support: Research projects of the Institute of Parasitology, BC ASCR (Z60220518 and LC522)

+ Corresponding author: moravec@paru.cas.cz

Received 12 June 2009

Accepted 1 September 2009 parasite of Chirostoma spp, with a limited distribution in the Pacific drainage system.

However, Caspeta-Mandujano (2005) listed S. osorioi also from Atherinella alvarezi (Díaz-Pardo), an atherinopsid fish endemic to Mexico; in addition to Michoacán (Lake Pátzcuaro), he reported this parasite from the Michol River in Chiapas, which belongs to the Atlantic drainage system. The presented modified species description and drawings of S. osorioi were taken over from the paper of Choudhury and Pérez-Ponce de León (2001). Accordingly, neither morphometric nor other data on the specimens from the host belonging to a different genus and originating from a different ocean drainage are available for comparison.

During parasitological dissections of freshwater fishes in Chiapas in January and April 2002, specimens of Spinitectus were collected from A. alvarezi. Results of their subsequent detailed study are presented below.

\section{MATERIALS AND METHODS}

Fish were collected by using a gill net from the

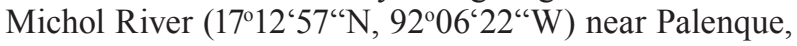
Chiapas, Southern Mexico in January and April of 2002. Nematodes recovered from the intestine were fixed in hot $4 \%$ formaldehyde solution. For light microscopical (LM) examination, they were cleared with glycerine. Drawings were made with the aid of a Zeiss microscope drawing attachment. Specimens used for scanning electron microscopy (SEM) were postfixed in 1\% osmium tetroxide, dehydrated through a graded ethanol series, critical point dried and sputter-coated with gold; they were examined using a JEOL JSM-6300 SEM at an ac- 
celerating voltage of $15 \mathrm{kV}$. All measurements are in micrometres unless otherwise stated. Fish names follow FishBase (Froese \& Pauly 2009).

S. osorioi Choudhury and Pérez-Ponce de León, 2001 (Figs 1-3)

Diagnosis: small, elongate, whitish nematodes. Cephalic end blunt; posterior end conical. Surface of body with transverse rings of spines; rings interrupted on both sides of body by lateral lines and also dorsally and ventrally, being thus composed of four separated sectors (rows) of spines (Fig. 1C); sometimes some rings incomplete or single spines present. Cuticle in region of first c.3-4 rows of spines somewhat inflated (Fig. 1A). First ring with 32-39 spines (Fig. 1C); more posterior rings almost equally spaced, with large, slender, posteriorly directed spines (Fig. 2A, B); largest spines in 4th-13th rows; rings of spines continue to some distance posterior to end of oesophagus, gradually diminishing posteriorly (Fig. 2G). Female tail smooth without spines. Oral aperture oval, slightly dorsoventrally elongated, surrounded by four poorly developed submedian labia forming
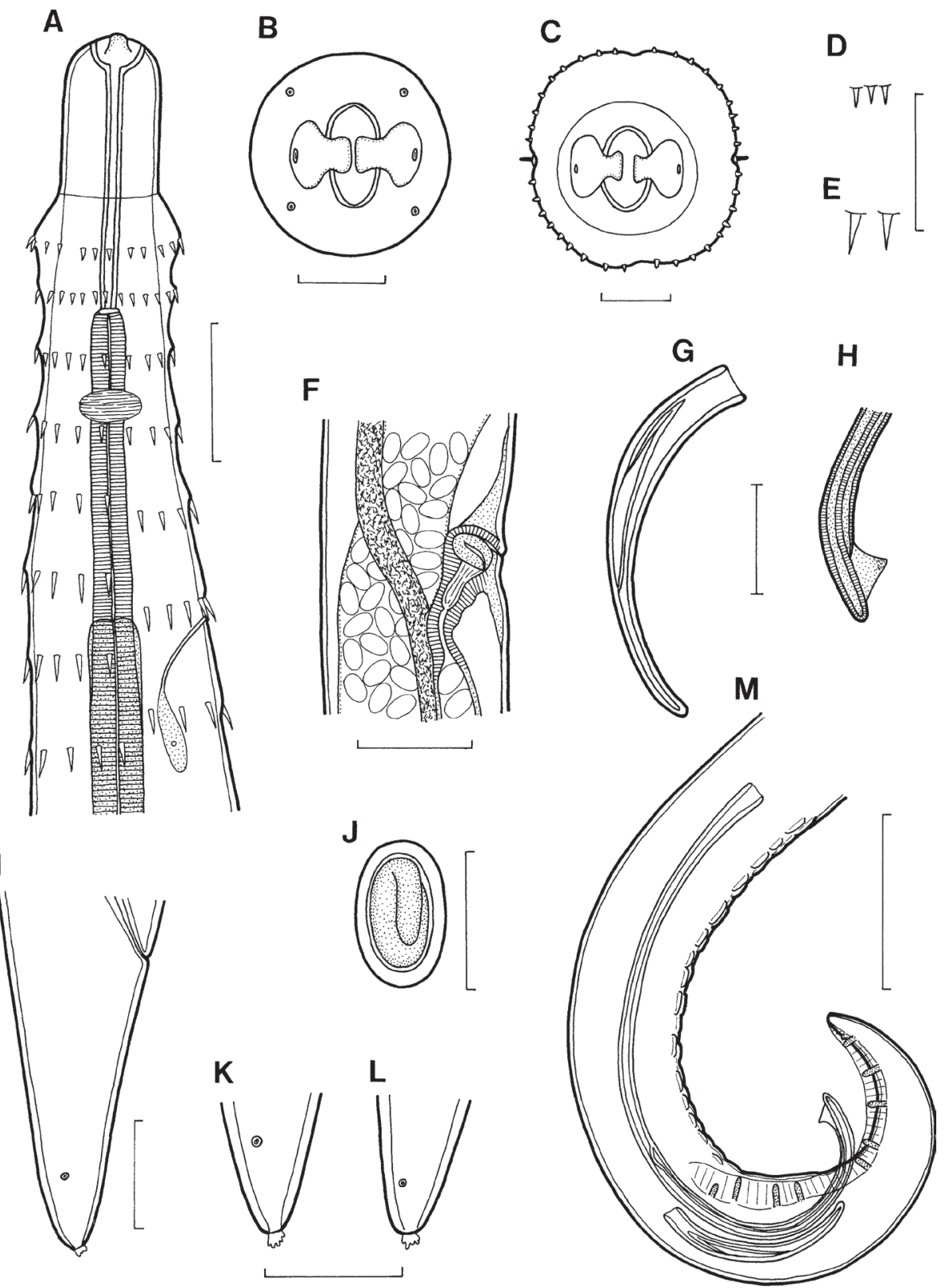

Fig. 1: Spinitectus osorioi Choudhury and Pérez-Ponce de León, 2001. A: anterior end of female, lateral view; B: mouth, apical view; C: cephalic end, apical view; D: spines of first ring; E: spines of 5th ring; F: region of vulva, lateral view; G: right spicule; H: distal end of left spicule; I: female tail, lateral view; J: fully developed egg; K, L: tail tip of female (different specimens), lateral views; M: posterior end of male, lateral view. Bars: A: $50 \mu \mathrm{m}$; B, C: $10 \mu \mathrm{m}$; D, E, G-L: $30 \mu \mathrm{m}$; F, M: $100 \mu \mathrm{m}$. 
dorsal and ventral margins of mouth. Single, narrow, simple curved sclerotised sublabium with a somewhat thickened free margin, attached by its base to inner surface of each labium. Lateral pseudolabia small, not enclosing most of mouth (Fig. 2C). In apical view, narrow inner parts of pseudolabia are expanded dorsoventrally, forming two (one laterodorsal and one lateroventral) narrow extensions on each pseudolabium. Inner margins of both pseudolabia straight, aligned dorsoventrally, parallel to each other. Pair of small lateral amphids and four small submedian cephalic papillae surround oral aperture (Figs 1B, 2C, E). Vestibule (stoma) long, with distinct anterior prostom in lateral view; vestibule ending posteriorly at level of 2 nd or between 2 nd-3rd rows of spines (Fig. 1A). Deirids small, finger-shaped, located between 1st and 2nd rows of spines (Figs 2D, $3 F, G)$. Oesophagus divided into anterior muscular and much longer, slightly wider posterior portion; length ratio of portions 1:2.5-4.7. Nerve ring encircles muscular oesophagus between 3th and 4th rings of spines. Excretory pore situated between 6th-7th rings of spines (Figs 1A, 2B). Males smaller than gravid females.

Male (3 specimens): length of body 3.10-3.67 mm; maximum width 81-102. First ring of spines situated 66-69 from anterior extremity, consists of 34-36 spines 3 long; maximum length of spines in more posterior (6th-9th) rings 6-9. Length of vestibule including prostom 93-102; funnelshaped prostom 6-9 long, 15 wide. Muscular oesophagus
201-225 long, maximum width 12-15; glandular oesophagus 564-579 long, maximum width 27-33; ratio 1:2.5-2.9. Length of vestibule and entire oesophagus represents 24$28 \%$ of whole body length. Nerve ring and excretory pore 138-171 and 156-210, respectively, from anterior extremity. Posterior end of body distinctly ventrally curved, provided with well-developed subventral alae. Ventral precloacal ridges (area rugosa) well developed, aligned in two rows (Fig. 3A), only additional short median ridge present in front of cloaca (Fig. 3D). Preanal papillae: four pairs, of which 1st and 2nd and 3rd and 4th pairs close to each other. Postanal papillae: five pairs of subventral papillae and one pair of ventral papillae situated at level of last subventrals. Pair of small phasmids situated ventrally somewhat posterior to ventral pair of postanal papillae (Fig. 3C). Large (left) spicule narrow, 420-465 long, with rounded distal tip bearing large ventral triangular outgrowth (Fig. 3B); length of shaft $219-240$ (52-54\% of spicule length). Small (right) spicule narrow, 105-111 long. Length ratio of spicules 1:3.8-4.2. Tail 126-135 long, with minute terminal cuticular spike (Fig. 3C).

Female (3 gravid specimens with mature eggs): length of body 6.92-7.63 mm; maximum width 159-180. First ring of spines 66-90 from anterior extremity, consists of 36-39 spines 3-4 long; maximum length of spines in more posterior (7th-13th) rings 12-14. Length of vestibule including prostom 105-111; funnel-shaped prostom 9-12 long, 18-21 wide. Muscular oesophagus 252-291 long,

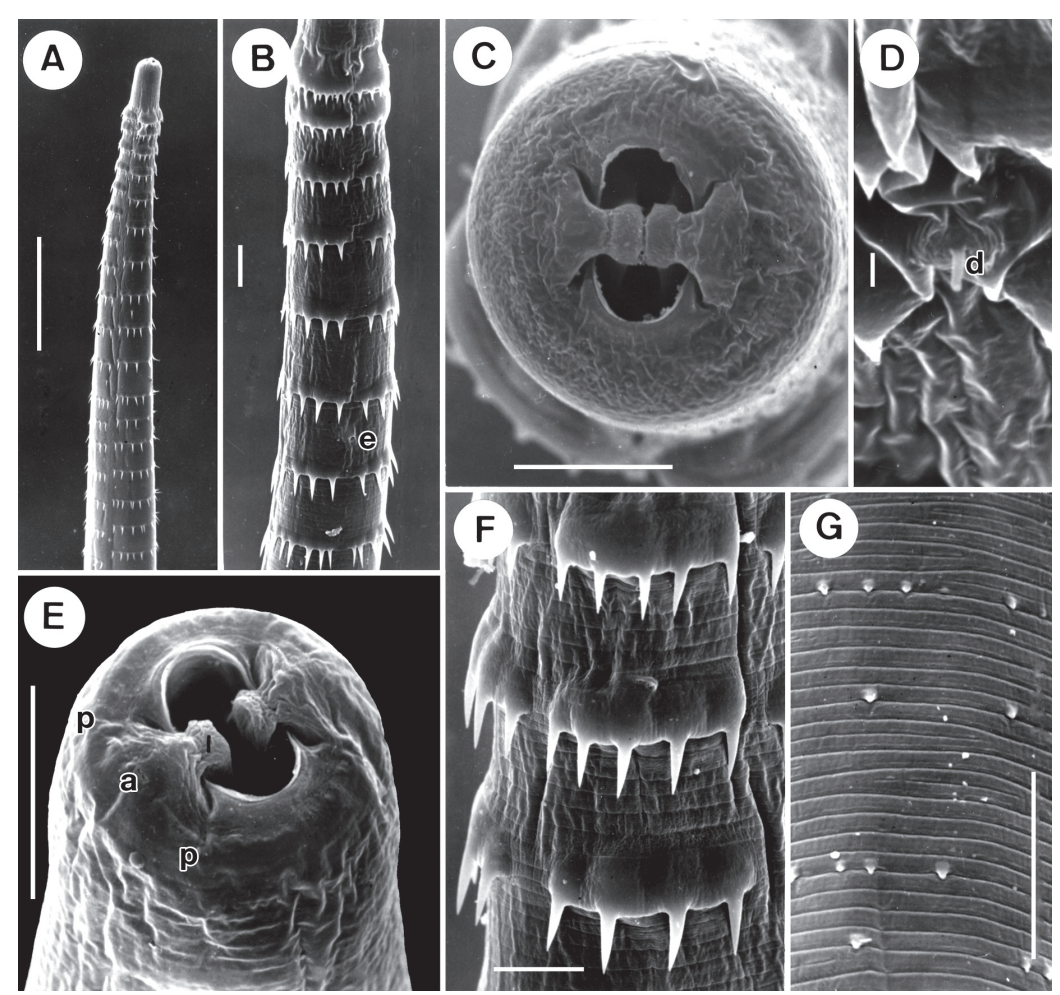

Fig. 2: Spinitectus osorioi Choudhury et Pérez-Ponce de León, 2001, scanning electron microscopy. A: anterior end of body, lateral view; a: amphid; B: anterior rings of spines to show position of excretory pore, ventral view; C: cephalic end, apical view; D: deirid; d: deirid; E: cephalic end, ventrolateral view; e: excretory pore; F: rows of spines on anterior part of body; G: spines on middle part of body; 1: pseudolabium; p: submedian cephalic papilla. Scale bars: A-C, F-I: $10 \mu \mathrm{m}$; D, E: $1 \mu \mathrm{m}$. 
maximum width 21; glandular oesophagus 972-1,290 long, maximum width 36-54; ratio 1:3.7-4.7. Length of vestibule and entire oesophagus represents $19-22 \%$ of body length. Nerve ring and excretory pore 147-150 and 225-255, respectively, from anterior extremity. Vulva equatorial or slightly preequatorial, situated 3.43-3.50 $\mathrm{mm}$ from anterior extremity (at $46-50 \%$ of body length). Vagina muscular, short, directed posteriorly from vulva. Amphidelphic. Ovaries narrow, long; coils of anterior ovary reaching anteriorly up to region of posterior end of oesophagus, those of posterior ovary reaching posteriorly nearly to end of intestine. Fully-developed eggs in uterus oval, thick-walled, each containing larva; size of eggs 33-36 × 18-21; thickness of shell 3; no filaments present (Fig. 1J). Tail conical, 93-114 long, with terminal mucron (4-6 long) bearing numerous minute processes (Figs 1K, L, 3E). Pair of phasmids located short distance anterior to tail tip (Fig. 3E).

Host - Gulf silverside, A. alvarezi (Atherinopsidae, Atheriniformes), body length 7-9 cm. Previously also reported from slender silverside, C. attenuatum (type host), pike silverside, C. estor and bigeye silverside, C. grandocule (all Atherinopsidae, Atheriniformes) (Choudhury \& Pérez-Ponce de León 2001, Lira-Guerrero et al. 2008).
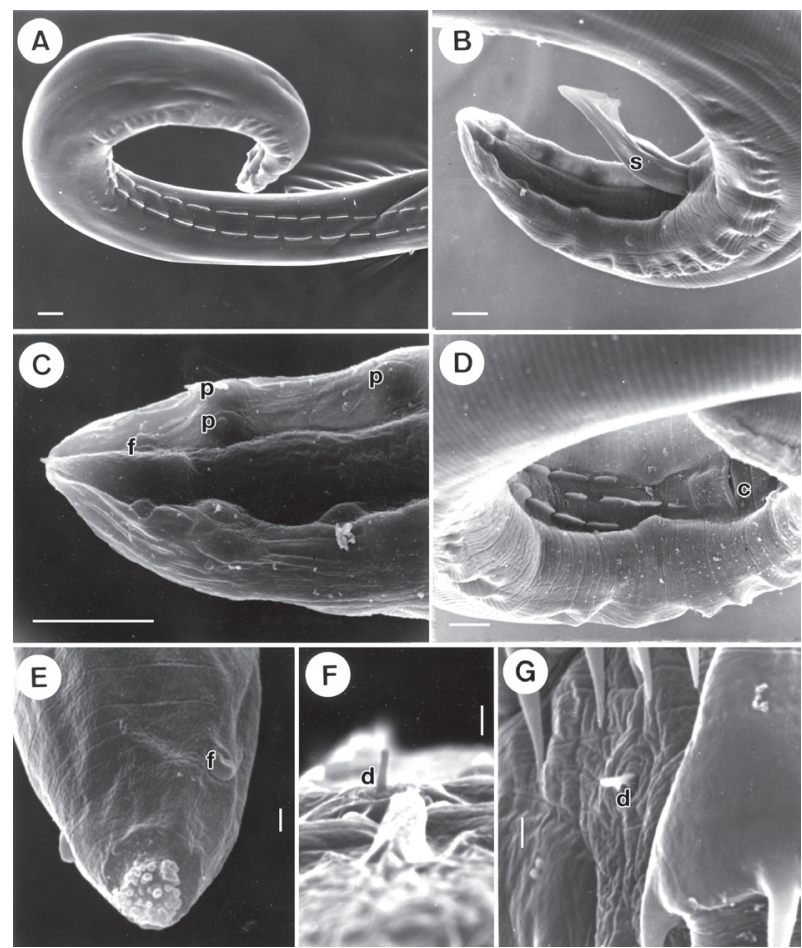

Fig. 3: Spinitectus osorioi Choudhury et Pérez-Ponce de León, 2001, scanning electron microscopy. A: caudal end of male to show area rugosa; B: tail of male, subventral view; C: posterior part of male tail, subventral view (note spine-like mucron on tail tip); c: cloacal aperture; D: region of cloaca, ventral view; d: deirid; E: tip of female tail, subventral view; F: shape of deirid, lateral view; f: phasmid; G: position of deirid between two anteriormost rows of cuticular spines, subdorsal view; p: postanal papilla; s: distal end of left spicule. Bars: A-D: $10 \mu \mathrm{m}$; E-G: $1 \mu \mathrm{m}$.
Site of infection - intestine (its middle part).

Locality - Michol River near Palenque (Usumacinta River basin), Chiapas, Southern Mexico. Choudhury and Pérez-Ponce de León (2001) and Lira-Guerrero (2008) reported it from Lakes Pátzcuaro and Zirahuén in Michoacán, Central Mexico.

Total prevalence and intensity - 64\% (14 fish infected/22 fish examined); 1-8 (mean 3-4) nematodes per fish.

Depository of voucher specimens - Institute of Parasitology, Biology Centre of the ASCR, České Budějovice (Cat. N-802).

\section{DISCUSSION}

The original description of S. osorioi (Choudhury \& Pérez-Ponce de León 2001), based on specimens from Chirostoma spp studied by LM and SEM made possible a detailed comparison with nematodes of the present material from $A$. alvarezi. The latter specimens were generally smaller (body length of males and females 3.10-3.67 vs. 3.25-5.55 and 6.92-7.63 vs. 6.10-9.75 $\mathrm{mm}$, respectively), which might reflect in their distinctly shorter spicules (420-465 and 105-111 vs. 480-520 and 120-160). As reported by Moravec (1979), the large (left) spicule of Spinitectus inermis (Zeder), a parasite of European eels, is considerably shorter in small specimens as compared to that in large specimens. However, also the fully developed eggs of specimens from $A$. alvarez $i$ were mostly smaller $(33-36 \times 18-20$ vs. $36-40 \times 20-23)$, whereas the female glandular oesophagus was somewhat longer (972-1,290 vs. 570-940). The recorded numbers of cuticular spines in the first ring were comparable to those in specimens from Chirostoma spp (34-39 vs. 28-44).

An important taxonomic feature in Spinitectus spp is the location of the vulva. Unfortunately, this is not mentioned in the original description of $S$. osorioi. The vulva in specimens from $A$. alvarezi was equatorial or slightly preequatorial.

Choudhury and Pérez-Ponce de León (2001) reported six pairs of postanal papillae in the male of $S$. osorioi from Chirostoma spp with the 6th pair (considered to be probably phasmids) being more ventromedial. However, as clearly visible in Fig. $3 \mathrm{C}$ of the present paper, in fact the last two pairs (one subventral and one ventral) are located at the same level, being followed by a pair of phasmids. Apparently, the above mentioned authors overlooked the ventral pair of papillae; the 6th pair reported by them was actually phasmids. Consequently, S. osorioi possesses a total of six pairs of postanal papillae and a pair of phasmids.

All the above mentioned biometrical differences may be ascribed either to the type of the fish host or the different geographical region, although it cannot be excluded that they are associated with the age of the worms. Nevertheless, these differences are not enough to establish a new species, but can be taken for the intraspecific variability of $S$. osorioi. Therefore, the specimens from A. alvarezi are considered to belong to this species.

Although Choudhury and Pérez-Ponce de León (2001) considered S. osorioi and its hosts Chirostoma spp endemic to some lakes in the Central Highland Plateau of Mexico (reported as the Mesa Central), historically belonging to a Pacific drainage, the present finding of 
this nematode in another atherinopsid fish (A. alvarezi) in the Atlantic drainage indicates a much more extensive nematode's distribution, supporting thus the theory of an original Gulf of Mexico derivation of atherinopsids in the Lerma Santiago River system (Choudhury \& PérezPonce de León 2001). The latter finding points out, first, that $S$. osorioi is not an endemic species of the Highland Plateau as previously presumed and, secondly, the finding suggests that this nematode could be a remnant of an ancient helminth community of atherinopsid fishes perhaps widely distributed in Mexican waters and presently recorded from two very disjunct locations.

It has been mentioned above that six species of Spinitectus are reported from freshwater fishes in Mexico: Spinitectus agonostomi Moravec and Baruš, Spinitectus humbertoi Caspeta-Mandujano and Moravec, Spinitectus mexicanus Caspeta-Mandujano, Moravec and SalgadoMaldonado, S. osorioi, Spinitectus tabascoensis Moravec, García-Magaña and Salgado-Maldonado and Spinitectus mariaisabelae Caspeta-Mandujano, Cabañas-Carranza and Salgado-Maldonado (Choudhury \& Pérez-Ponce de León 2001, Moravec et al. 2002, Caspeta-Mandujano 2005, Caspeta-Mandujano et al. 2007). All these species are known only from Mexico, except for S. agonostomi distributed also in Cuba and Guadeloupe, Lesser Antilles (Moravec \& Baruš 1971, Petter et al. 1977). S. osorioi is easily distinguished from nearly all of them (except $S$. mariaisabelae), as well as from all other congeneric species, by the presence of a terminal mucron with numerous pointed processes on the female tail.

\section{Key to species of Spinitectus parasitizing freshwater fishes in Mexico}

1. Surface of mature eggs with two equatorial hemispherical globules (floats). Larger (left) spicule very long, up to $1.32 \mathrm{~mm}$. Excretory pore located between 5th-6th rings of cuticular spines. Parasitic in Mugilidae (Agonostomus); reported also from Poeciliidae (Belonesox), Characidae (Bramocharax), Centropomidae (Centropomus), Cichlidae (Cichlasoma, Vieja) and Eleotrididae (Dormitator); Veracruz and Jalisco ... S. agonostomi

- Surface of mature eggs smooth, without any globules or filaments. Parasitic in hosts belonging to other families

2. Larger (left) spicule about $1 \mathrm{~mm}$ long, with markedly long ventral digital outgrowth on distal end. Excretory pore between 7 th-8th rings of cuticular spines. Tail tip of female bearing several small digital processes. Parasitic in Cyprinodontidae (Profundulus) in Chiapas . S. mariaisabelae

- Larger (left) spicule shorter than $600 \mu \mathrm{m}$, without conspicuous digital outgrowth on distal end................... 3

3. Cuticular spines in first ring 12-20 in number. Larger (left) spicule 211-333 $\mu \mathrm{m}$ long. Excretory pore between 5th-6th rings of spines. Parasitic in Poeciliidae (Heterandria) in Veracruz ............................ mexicanus

- Cuticular spines in first ring not less than 28 ....... 4

4. Gravid females 3-4 mm long. Excretory pore between 7th-8th rings of spines. Larger (left) spicule 396-
$412 \mu \mathrm{m}$ long. Parasitic in Cyprinodontidae (Profundulus) in Guerrero............................................ S. humbertoi - Gravid females not shorter than $6 \mathrm{~mm}$. Excretory pore between 6th-7th rings of spines ...............................

5. Maximum length of cuticular spines $24 \mu \mathrm{m}$. Larger (left) spicule $213 \mu \mathrm{m}$ long. Female tail tip with knob-like mucron. Parasitic in Ictaluridae (Ictalurus) in Tabasco .. S. tabascoensis

- Maximum length of cuticular spines $15 \mu \mathrm{m}$. Larger (left) spicule 420-520 $\mu \mathrm{m}$ long. Female tail tip with mucron bearing numerous pointed processes. Parasitic in Atherinopsidae (Chirostoma, Atherinella) in Michoacán and Chiapas. S. osorioi

\section{ACKNOWLEDGEMENTS}

To Rocío Rodiles Hernández, from ECOSUR San Cristóbal Las Casas Chiapas, and Eduardo Soto Galera, from ENCB IPN México DF, for their interest and kind assistance with the project, to students of the Institute of Biology, UNAM, México City, for their help with collecting and examining fishes in Chiapas, to the staff of the Laboratory of Electron Microscopy, Institute of Parasitology, BC ASCR, České Budějovice, for their technical assistance, and to Irena Husáková and Blanka Škoríková, technicians of the same Institute, for their help with illustrations.

\section{REFERENCES}

Caspeta-Mandujano JM 2005. Nematode parasites of freshwater fish in Mexico: key to species, descriptions and distribution, Facultad de Ciencias Biológicas, Universidad Autónoma del Estado de Morelos, Cuernavaca, $175 \mathrm{pp}$.

Caspeta-Mandujano JM, Cabañas-Carranza G, Salgado-Maldonado G 2007. Spinitectus mariaisabelae n. sp. (Nematoda: Cystidicolidae) from the intestine of the freshwater fish Profundulus punctatus (Cyprinodontiformes) in Mexico. Helminthologia 44: 103-106.

Choudhury A, Pérez-Ponce de León G 2001. Spinitectus osorioi n. sp. (Nematoda: Cystidicolidae) from Chirostoma spp (Osteichthyes: Atherinidae) in Lake Pátzcuaro, Michoacán, México. J Parasitol 87: 648-655.

Espinosa-Huerta E, García-Prieto L, Pérez-Ponce de León G 1996. Helminth community structure of Chirostoma attenuatum (Osteichthyes: Atherinidae) in two Mexican lakes. Southwest Natur 41: 288-292.

Froese R, Pauly D 2009. FishBase. Available from: http://www.fishbase.org/ [updated January 2009; cited 12 June 2009].

Lira-Guerrero G, García-Prieto L, Pérez-Ponce de León G 2008. Helminth parasites of atherinopsid freshwater fishes (Osteichthyes: Atheriniformes) from Central Mexico. Rev Mex Biodiver 70: 325-331.

Moravec F 1979. Redescription of the nematode Spinitectus inermis parasitic in eels, Anguilla anguilla, of Europe. Acta Soc Zool Bohemoslov 43: 35-42.

Moravec F, Baruš V 1971. Studies on parasitic worms from Cuban fishes. Acta Soc Zool Bohemoslov 35: 56-74.

Moravec F, García-Magaña L, Salgado-Maldonado G 2002. Spinitectus tabascoensis sp. nov. (Nematoda: Cystidicolidae) from Ictalurus furcatus (Pisces) in Southeastern Mexico. Acta Parasitol 47: 224-227.

Petter A-J, Golvan YJ, Tcheprakoff R 1977. Nématodes de poissons de rivière en Guadeloupe. Bull Mus Nat Hist Nat, Ser 3, Zool 298: 159-171. 